\title{
Determination of Methylene Groups in Disulfide and Methylene Sulfide Crosslinks in Polycaprolactam Fibers
}

\author{
Stephen D. Bruck* \\ (January 23, 1962)
}

\begin{abstract}
Recent publications from this laboratory describe some unusual properties, such as crimping and helical coiling, induced by heterogeneous, chemical crosslinking of polycaprolactam fibers. The following crosslinks are involved:<smiles>CC(=O)N(C)CSCSCN(C)C(C)=O</smiles>

and<smiles>CC(=O)NCSCCSCN(C)C(C)=O</smiles>

It has been found that the $-\mathrm{CH}_{2}-$ groups in these crosslinks can be hydrolyzed to yield one equivalent of formaldehyde for each equivalent of hydrolyzable methylene group. This permits the application of the chromotropic acid method for determining formaldehyde to the estimation of the number of crosslinks in the fiber, when used in conjunction with a previously reported conductometric method for the determination of sulfhydryl groups. A general method has been worked out, with special attention to sulfur-containing degradation products (of the crosslinks) that may interfere with the analysis.
\end{abstract}

\section{Introduction}

Recent publications $[1 \text { to } 4]^{1}$ from this laboratory describe some unusual properties, such as crimping and helical coiling of polycaprolactam (nylon-6) fibers, induced by heterogeneous, chemical crosslinking in the swollen state. Also under study [5] are other fundamental properties of crosslinked polymer systems for which it is important to estimate the number of crosslinks. In another paper [6], a conductometric method is discussed for the determination of sulfhydryl groups in polycaprolactam fibers having disulfide and alkylene sulfide crosslinks. Although it was shown in previous communications $[7,8]$ that, for a well-defined, fairly uniformly crosslinked fiber, the number of equivalents of crosslinks may be calculated from swelling measurements, such an approach can not be entirely relied upon when the crosslinking density across the cross section of the

\footnotetext{
*Present address: Goddard Space Flight Center, National Aeronauties and Space Administration, Greenbelt, Md.

1 Figures in brackets indicate the literature references at the end of this paper.
}

fiber is nonuniform, as in the present case. Thus, a chemical approach that can specifically identify the hydrolyzable methylene $\left(-\mathrm{CH}_{2}-\right)$ components of a crosslink could serve as a basis for the estimation of the number of crosslinks in conjunction with sulfhydryl group determination.

The following crosslinks are primarily involved:<smiles>CC(=O)N(C)CCSCSCCSCN(C)C(C)=O</smiles> 
For the sake of comparison, another type of crosslink [9] was also studied, having the following structure:

IV.<smiles>CC(=O)N(C)CN(C)C(C)=O</smiles>

It has been found that the methylene $\left(-\mathrm{CH}_{2}-\right)$ groups between the nitrogen and sulfur atoms, and the methylene groups between two sulfur atoms, as well as the methylene groups between two nitrogen atoms can be hydrolyzed under acidic conditions at room temperature to yield formaldehyde. Accordingly, per equivalent of crosslink, structure I will yield two equivalents of formaldehyde structure II three equivalents, structure III two equivalents, and structure IV one equivalent.

A sensitive method for the determination of formaldehyde is based on its condensation with chromotropic acid (4,5-dihydroxy-2,7-naphthalenedisulfonic acid). Eegriwe [10] was the first to propose the use of chromotropic acid as a spot test for formaldehyde. Later, the reaction was investigated by several workers, including Bricker and Johnson [11], Boyd and Logan [12], and MacFadyen [13]. MacFadyen applied the chromotropic acid method to the determination of formaldehyde in biological mixtures and found that the reaction product exhibits three absorption bands at 380,480 , and $570 \mathrm{~m} \mu$, the last band being the most intense. The chromotropic acid method for determining formaldehyde gives essentially equivalent results to the well-known sodium sulfite method [14], but the former has the advantage of being very sensitive and requiring only small samples. A technique for the determination of formaldehyde yield of chemically treated cellulose fibers using chromotropic acid was described by Roff [15].

In the present work, special attention was focused on applying the chromotropic acid method to the analytical characterization of crosslinked polymer systems that, due to certain degradative reactions, may have interfering substances present. Consequently, the following parameters were studied: (1) hydrolytic conditions for the liberation of formaldehyde, (2) conditions for optimum color development, (3) the effect of chromotropic acid concentration on the absorption maximum at $570 \mathrm{~m} \mu$, and (4) the effect of acidity on color development.

\section{Experimental Procedure}

\subsection{Hydrolysis to Formaldehyde}

To insure a correct analysis of the crosslinked systems, all hydrolyzable methylene groups in the crosslinks must be transformed into formaldehyde. The conditions that affect complete hydrolysis of these groups are not only a function of the relative hydroly tic stability of the bonds but also of the accessibility of the hydrolyzing agent. In highly crosslinked systems, especially if additional radiation-induced crosslinks are present in the system, the hydrolysis of the chemically introduced crosslinks may be retarded due to the tight network structure of the polymer. It is therefore necessary to develop conditions that will facilitate complete hydrolysis of the crosslinks. Table 1 summarizes the data for such a system that has been subjected to two kinds of hydrolytic conditions.

TABLE 1. The effect of hydrolytic conditions on the liberation of formaldehyde from polycaprolactam fibers with various amounts of crosstinks

\begin{tabular}{|c|c|c|c|c|c|c|}
\hline \multirow[b]{2}{*}{$\begin{array}{l}\text { Sample a } \\
\text { No. }\end{array}$} & \multicolumn{2}{|c|}{ Hydrolytic condition } & \multirow{2}{*}{$\begin{array}{c}\mathrm{Ab}^{\mathrm{b}} \\
\mathrm{HCHO}\end{array}$} & \multicolumn{2}{|c|}{ Hydrolytic condition } & \multirow{2}{*}{$\begin{array}{c}\mathrm{B}^{\mathrm{c}} \\
\mathrm{HCHO}\end{array}$} \\
\hline & $\begin{array}{c}\text { Polymer } \\
\text { weight }\end{array}$ & $\begin{array}{c}\text { Absorbancy } \\
\left(\log I_{\mathrm{o}} / I\right) \\
\text { at } 570 \mathrm{~m} \mu\end{array}$ & & $\begin{array}{l}\text { Polymer } \\
\text { weight }\end{array}$ & $\begin{array}{c}\text { Absorbancy } \\
\left(\log I_{\mathrm{o}} / I\right) \\
\text { at } 570 \mathrm{~m} \mu\end{array}$ & \\
\hline $\begin{array}{l}1 \\
2 \\
3 \\
4 \\
5 \\
6\end{array}$ & $\begin{array}{l}m g \\
17.68 \\
17.18 \\
17.27 \\
17.90 \\
17.05 \\
17.74\end{array}$ & $\begin{array}{r}0.052 \\
.155 \\
.116 \\
.090 \\
.061 \\
.078\end{array}$ & $\begin{array}{r}\text { Percert } \\
1.1 \\
3.4 \\
2.5 \\
1.9 \\
1.3 \\
1.6\end{array}$ & $\begin{array}{l}m g \\
15.53 \\
16.92 \\
17.29 \\
16.06 \\
16.85 \\
16.23\end{array}$ & $\begin{array}{r}0.082 \\
.210 \\
.179 \\
.143 \\
.160 \\
.113\end{array}$ & $\begin{array}{r}\text { Percent } \\
1.9 \\
4.6 \\
3.8 \\
3.3 \\
3.5 \\
2.5\end{array}$ \\
\hline
\end{tabular}

a Sample No. indicates fibers with various degrees of crosslinking.

b $\mathrm{A}=$ addition of $30 \mathrm{ml}$ conc. (96\%) sulfuric acid and $15 \mathrm{ml}$ water, followed by standing at room temperature for 10 to 15 mins.

e $\mathrm{B}=$ addition of $15 \mathrm{ml}$ conc $(96 \%)$ sulfuric acid, allowed to stand at room temperature for 10 to $15 \mathrm{~min}$, followed by addition of $15 \mathrm{ml}$ water and standing for 45 to $60 \mathrm{~min}$ at room temperature.

or 45 to $60 \mathrm{~min}$ at room temperature.
No further increase in percent formaldehyde was observed upon either further standing at room temperature or heating at $60^{\circ} \mathrm{C}$ for $30 \mathrm{~min}$.

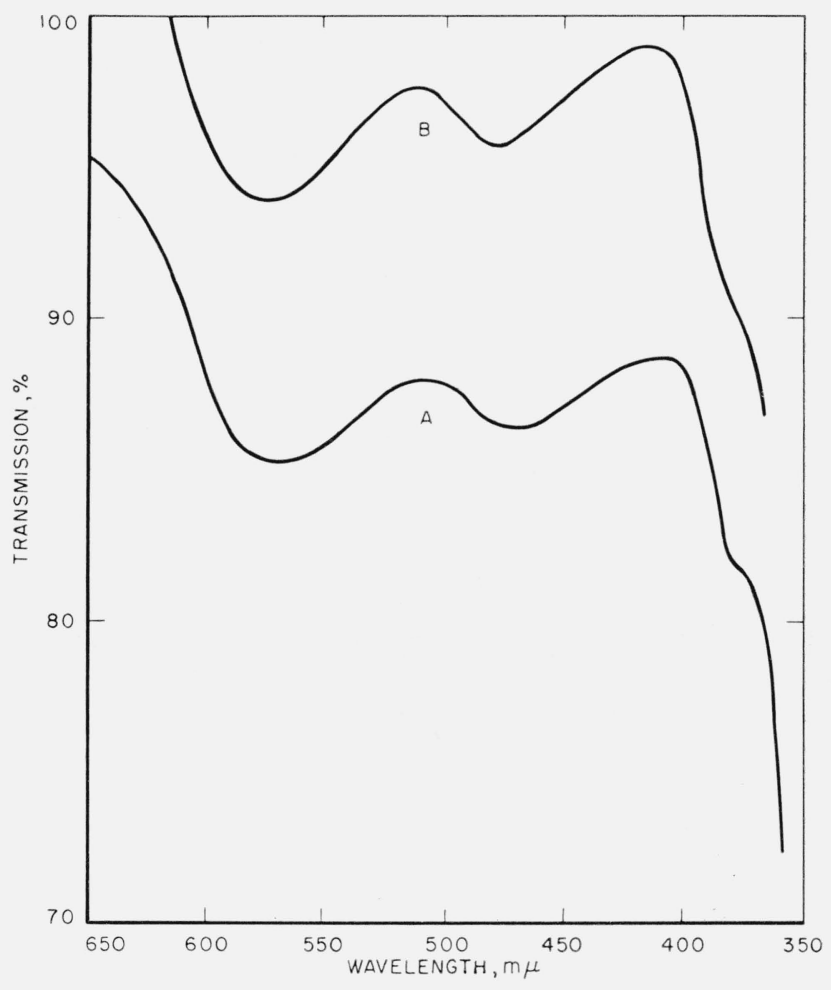

Figure 1. Transmission curves. Curve $A$ represents the reaction product of pure formaldehyde stock solution
with chromotropic acid. Curve $B$ represents the reaction product of formaldewith chromotropic acid. Curve $B$ represents the reaction product of formalde(Curve $B$ is displaced upward by approximately 7 percent to avoid overlap.) 


\subsection{Conditions for Optimum Color Development}

The general applicability of the chromotropic acid method to the analytical characterization of these crosslinked systems is illustrated by figure 1 . Absorption curve $A$ is that of the reaction product of pure formaldehyde stock solution with chromotropic acid reagent. Curve $B$ (displaced upward by approximately $7 \%$ to avoid overlap with curve $A$ ) represents a typical absorption curve of the reaction product of formaldehyde liberated by hydrolysis of sulfur-containing crosslinks in polycaprolactam (described above).

Both MacFadyen [13] and Bricker and Johnson [11] recommended heating at $100{ }^{\circ} \mathrm{C}$ for $30 \mathrm{~min}$ to develop the optimum color intensity. However, it has been established in the present study that allowing the solution to stand at room temperature for 3 to $4 \mathrm{hr}$ after the addition of chromotropic acid is equivalent to such a heating period. Treatment beyond 3 to $4 \mathrm{hr}$ is unnecessary, as shown in table 2 .

TABLE 2. The effect of heat on color development

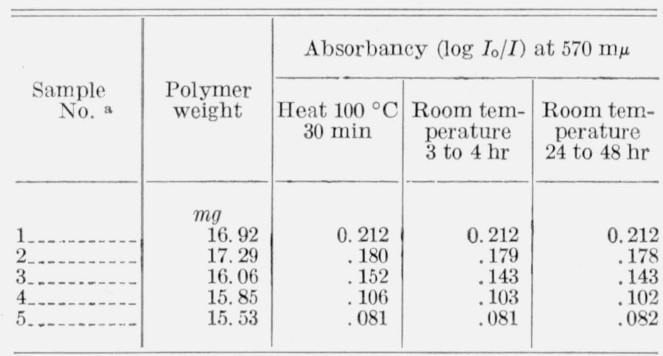

a Sample No. indicates polycaprolactam fibers with various degrees of crosslinking.

\subsection{Effect of Concentration of Chromotropic Acid Reagent}

Bricker and Johnson [11] showed that for the analysis of pure formaldehyde, a minimum weight ratio of reagent to formaldehyde of 500 to 1 is necessary. In the present study it was found that interfering substances, as a result of certain degradative reaction [5], markedly suppress the absorption peak at $570 \mathrm{~m} \mu$. This effect can be overcome, however, by the use of a very large excess of reagent, as summarized in table 3 . The exact nature of

TABLE 3. The effect of chromotropic acid concentration on absorbancy at $570 \mathrm{m \mu}$ in the presence of interfering substances

\begin{tabular}{|c|c|c|c|c|}
\hline \multirow[b]{2}{*}{$\begin{array}{c}\text { Sample a } \\
\text { No. }\end{array}$} & \multirow[b]{2}{*}{$\begin{array}{c}\text { Polymer } \\
\text { weight }\end{array}$} & \multicolumn{3}{|c|}{ Absorbaney $\left(\log I_{\mathrm{o}} / I\right)$ at $570 \mathrm{~m} \mu$} \\
\hline & & $\begin{array}{c}0.5 \mathrm{ml} \text { of } 4 \% \\
\text { chromo- } \\
\text { tropic acid }\end{array}$ & $\begin{array}{c}0.5 \mathrm{ml} \text { of } 10 \% \\
\text { chromo- } \\
\text { tropic acid }\end{array}$ & $\begin{array}{c}1.0 \mathrm{ml} \text { of } 10 \% \\
\text { chromo- } \\
\text { tropic acid }\end{array}$ \\
\hline & $\operatorname{mg}_{16.60}$ & 0.246 & 0.250 & 0.251 \\
\hline & $\begin{array}{l}10.00 \\
17.29\end{array}$ & $\begin{array}{l}0.270 \\
167\end{array}$ & $\begin{array}{r}0.200 \\
178\end{array}$ & $\begin{array}{r}0.231 \\
.179\end{array}$ \\
\hline & 16.85 & 139 & 162 & 160 \\
\hline & 16. 23 & .088 & .112 & .113 \\
\hline & 15.53 & .070 & .080 & .081 \\
\hline & 15.85 & .071 & .088 & 089 \\
\hline
\end{tabular}

a Sample No. indicates polycaprolactam fibers with various degrees of crosslinking. these interfering substances has not been determined, but they are likely to be oxidation products of the sulfur-containing crosslinks and possibly other aldehydes resulting from the oxidation.

\subsection{Effect of Acidity on Color Development}

The acidity of the solution after the chromotropic acid reagent has been added is an important factor in the development of maximum color intensity. Table 4 summarizes the results with disulfide-crosslinked polycaprolactam fibers that had been subjected to degradative treatment [5]. The data indicate that the absorbancy at $570 \mathrm{~m} \mu$ is suppressed by the addition of water to the sample containing the chromotropic acid-sulfuric acid mixture. Furthermore, after heating the acidified sample at $100{ }^{\circ} \mathrm{C}$ for $30 \mathrm{~min}$, the addition of water suppresses the color intensity even more than when the initial color formation is carried out at room temperature. On the other hand, the intensity of the color formation for those crosslinked samples that do not contain sulfur in the crosslink is practically unaffected by the presence of water, as indicated by the data in table 5 . It is therefore probable that this suppression of color intensity is due to oxidation products of the sulfurcontaining crosslinks. It should be also noted that, whereas the visual magenta color of the chromotropic acid-formaldehyde reaction product appears to become yellowish on prolonged standing, the absorption peak at $570 \mathrm{~m} \mu$ remains unchanged.

TABLE 4. The effect of acidity on absorbancy at $570 \mathrm{~m} \mu$ for methylene disulfide crosslinked polycaprolactam fibers

\begin{tabular}{|c|c|c|c|c|c|}
\hline \multirow{3}{*}{$\begin{array}{c}\text { Sample } \\
\text { No. a }\end{array}$} & \multirow{3}{*}{$\begin{array}{l}\text { Polymer } \\
\text { weight }\end{array}$} & \multicolumn{4}{|c|}{ Absorbancy $\left(\log I_{\mathrm{o}} / I\right)$ at $570 \mathrm{~m} \mu$} \\
\hline & & \multicolumn{2}{|c|}{ Heat, $100{ }^{\circ} \mathrm{C}, 30 \mathrm{~min}$} & \multicolumn{2}{|c|}{ Room temperature $3-4 \mathrm{hr}$} \\
\hline & & $\begin{array}{l}\text { Conc. } \\
\mathrm{H}_{2} \mathrm{SO}_{4}-\mathrm{H}_{2} \mathrm{O} \text { b }\end{array}$ & $\begin{array}{l}\text { Conc. } \\
\mathrm{H}_{2} \mathrm{SO}_{4} \text { c }\end{array}$ & $\begin{array}{c}\text { Conc. } \\
\mathrm{H}_{2} \mathrm{SO}_{4}-\mathrm{H}_{2} \mathrm{O} \text { b }\end{array}$ & $\begin{array}{l}\text { Conc. } \\
\mathrm{H}_{2} \mathrm{SO}_{4}{ }^{\circ}\end{array}$ \\
\hline $1 \ldots$ & $\begin{array}{l}m g \\
24.24 \\
23.32\end{array}$ & $\begin{array}{r}0.139 \\
.091\end{array}$ & $\begin{array}{r}0.160 \\
.109\end{array}$ & $\begin{array}{r}0.150 \\
.099\end{array}$ & $\begin{array}{r}0.161 \\
.109\end{array}$ \\
\hline
\end{tabular}

a Sample No. indicates fibers with various degrees of crosslinking.

b $5 \mathrm{ml}$ aliquot of sample plus $30 \mathrm{ml}$ cone. $(96 \%) \mathrm{H}_{2} \mathrm{SO}_{4}$ and $1.0 \mathrm{ml}$ of 10 percent chromotropic acid. After 3 to 4 hr dilute to $50 \mathrm{ml}$ with dist. $\mathrm{H}_{2} \mathrm{O}$.

c $5 \mathrm{ml}$ aliquot of sample plus $30 \mathrm{ml}$ conc. $(96 \%) \mathrm{H}_{2} \mathrm{SO}_{4}$ and $1.0 \mathrm{ml}$ of 10 percent chromotropic acid. After 3 to $4 \mathrm{hr}$ dilute to $50 \mathrm{ml}$ with conc. $(96 \%) \mathrm{H}_{2} \mathrm{SO}_{4}$.

TABLE 5. The effect of acidity on absorbancy at $5 \% 0 \mathrm{m \mu}$ for methylene-crosstinked polycaprolactam fiber

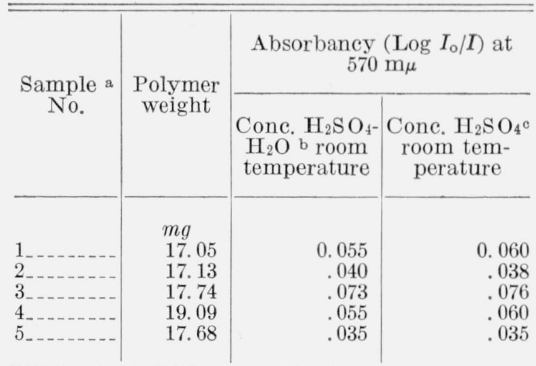

a Sample No. indicates fibers with various degrees of crosslinking.

o $5 \mathrm{ml}$ aliquot of sample plus $30 \mathrm{ml}$ conc. $(96 \%) \mathrm{H}_{2} \mathrm{SO}_{4}$ and $1.0 \mathrm{ml}$ of $10 \%$ chromotropic acid. After 3 to 4 hrs dilute to $50 \mathrm{ml}$ with distilled water.

c $5 \mathrm{ml}$ aliquot of sample plus $30 \mathrm{ml}$ conc. $(96 \%) \mathrm{H}_{2} \mathrm{SO}_{4}$ and $1.0 \mathrm{ml}$ of 10 percent chromotropic acid. After 3 to 4 hrs, dilute to $50 \mathrm{ml}$ with conc. (96\%). $\mathrm{H}_{2} \mathrm{SO}_{4}$. 
Under condition $A$, samples with various degrees of crosslinking were treated with $30 \mathrm{ml}$ of conc. $(96 \%)$ sulfuric acid and $15 \mathrm{ml}$ of distilled water, and allowed to stand at room temperature for approximately 15 min. In procedure $B$, the samples were treated first with $15 \mathrm{ml}$ conc. (96\%) sulfuric acid, allowed to stand for approximately $15 \mathrm{~min}$, and then $15 \mathrm{ml}$ of distilled water was added and the solution was allowed to stand for 45 to $60 \mathrm{~min}$. The results in table 1 indicate that condition $A$ was insufficient to bring about complete hydrolysis of the crosslinks, as shown by the low values in the percent of formaldehyde. On the other hand, condition $B$ resulted in an increase in the liberated formaldehyde. Since no further increase in the amount of formaldehyde was noted by longer standing or by heating the polymer in the acid solution at $60{ }^{\circ} \mathrm{C}$, it appears that condition $B$ is sufficient to bring about complete hydrolysis of the crosslinks.

Later it was found advantageous to let the crosslinked polymer soak in conc. $(96 \%)$ sulfuric acid for two hrs, and then to add enough water to make the solution 48 to 50 percent with respect to the sulfuric acid and to allow the solution to stand overnight at room temperature in a stoppered flask.

\section{Recommended Procedure}

A 15 to $25 \mathrm{mg}$ dried fiber sample (expected formaldehyde concentration, on hydrolysis, of up to $6 \%$ ) is placed in a $250 \mathrm{ml}$ volumetric flask, $15 \mathrm{ml}$ of conc. $(96 \%)$ sulfuric acid is added, the flask is stoppered and the polymer is allowed to soak in the acid solution for approximately $2 \mathrm{hr}$ at room temperature. At the end of this period $15 \mathrm{ml}$ of distilled water is carefully added with mixing, the flask is stoppered, and the solution is allowed to stand for at least 6 hr at room temperature. Then, enough distilled water is added to bring the volume to $250 \mathrm{ml}$, and the solution is allowed to come to room temperature. The volume is again adjusted to $250 \mathrm{ml}$, if necessary, and mixed. In the case of fiber samples that contain $\mathrm{TiO}_{2}$ as delustrant, $15 \mathrm{ml}$ of the above solution is centrifuged for approximately $45 \mathrm{~min}$ at approximately 4,500 rpm using a conical shaped centrifuge tube. If no $\mathrm{TiO}_{2}$ is present, the solution is centrifuged for only $15 \mathrm{~min}$ to remove any undissolved matter. Then, $5 \mathrm{ml}$ of the centrifuged solution is pipeted into a $50 \mathrm{ml}$ volumetric flask, $1.0 \mathrm{ml}$ of a 10 percent (by weight), filtered solution of chromo- tropic acid (in water) is added, followed by $30 \mathrm{ml}$ of conc. $(96 \%)$ sulfuric acid with mixing. The solution develops a magenta color within a few seconds; the flask is stoppered and allowed to stand at room temperature for at least $3 \mathrm{hr}$. At the end of this period, the contents of the flask are diluted to $50 \mathrm{ml}$ with conc. (96\%) sulfuric acid and mixed. The solution is allowed to stand for $0.5 \mathrm{hr}$, the volume is adjusted with conc. sulfuric acid, as needed, and the absorbancy $\left(\log I_{0} / I\right)$ is read off at $570 \mathrm{~m} \mu$, using a spectrophotometer and a reagent blank. The concentration of formaldehyde $(\mathrm{mg} / \mathrm{ml})$ is determined from a calibration curve and the percent formaldehyde is calculated from the following equation:

$$
\% \text { Formaldehyde }=\frac{\mathrm{mg} \mathrm{HCHO} / \mathrm{ml} \times 2500 \times 100}{\mathrm{mg} \text { of sample }}
$$

Part of this work was carried out with the technical assistance of Lawrence S. Phillips, a student at Swarthmore College, during his tenure as a student trainee in the Textiles Section of the National Bureau of Standards during the summer of 1961 . The author also thanks Donald H. Becker for his assistance in this work.

\section{References}

[1] S. D. Bruck, J. Research NBS 65A (Phys. and Chem.), No. 6, 489 (Nov.-Dec. 1961).

[2] S. D. Bruck, J. Research NBS 66A (Phys. and Chem.), No. 1, 77 (Jan.-Feb. 1962).

[3] NBS Tech. News Bull., Structural Modification of Synthetic Fibers, 45, 152 (1961).

[4] Chem. and Eng. News, Crosslinks crimp and coil nylon-6 fiber, pp. 50-51 (Oct., 1961).

[5] S. D. Bruck, to be published.

[6] S. D. Bruck and S. M. Bailey, J. Research NBS $66 \mathbf{A}$ (Phys. and Chem.), No. 2, 185 (1962).

[7] S. D. Bruck, J. Polymer Sci. 55, S29 (1961).

[8] S. D. Bruck, J. Research NBS 65A (Phys. and Chem.), No. 6, 485 (Nov.-Dec. 1961).

[9] B. Graham and O. E. Schupp, U.S. Patent 2,540,726.

[10] E. Eegriwe, Z. Anal. Chem. 110, 22 (1937)

[11] C. E. Bricker and H. R. Johnson, Anal. Chem. 17, 400 (1945).

[12] M. J. Boyd and M. A. Logan, J. Biol. Chem. 146, 279 (1942).

[13] D. A. MacFadyen, J. Biol. Chem. 158, 107 (1945).

[14] J. F. Walker, Formaldehyde, p. 257 (Reinhold Publishing Corp., New York, 1944).

[15] W. J. Roff, J. Text. Inst. 47, T 309 (1956).

(Paper 66A3-159) 